American J. of Engineering and Applied Sciences 1 (4): 266-273, 2008

ISSN 1941-7020

(C) 2008 Science Publications

\title{
A Sliding Mode Command for a System of Coupled Reservoirs
}

\author{
${ }^{1}$ Riadh Gamoudi, ${ }^{1,2}$ Mahmoud Ellouze, ${ }^{1,3}$ Abdelkader Mami \\ ${ }^{1}$ Laboratory of Analysis and Commands Systems, 3100, \\ Manufacture of Tobacco of Kairouan, Tunisia \\ ${ }^{2}$ Superior Institute of Technology and Data processing, 2080, Ariana, Tunisia \\ ${ }^{3}$ Department of Physics, Faculty of Sciences of Tunis, Electronic Laboratory, 2092 El Manar Tunis, Tunisia
}

\begin{abstract}
This study consisted to determine a discreet order by sliding method that was applied on a regulation procedure of a formed level by communicating reservoirs. The model that represents the system is determined by parametric identification based on the algorithm of the recursive least square with forgetfulness factor. Problem statement: The purpose is to develop a robust order that assuring the stability of the system autonomously of his initial state or of his environment. Approach: The first step consist to model the process, afterward, we developed the order. Results: We developed a command which permit to conduct the system towards a desired state (chosen state, an equilibrium point in our case) and ensured its stability in this zone whatever the conditions on the system. Conclusions: the hardiness of the order has been proved as a result of the introduction of an external perturbation on the process. But this order will be able again to improve also the non-controllable defects.
\end{abstract}

Key words: Sliding mode, coupled reservoirs, recursive least squares

\section{INTRODUCTION}

The majority of the industrial systems are a non linear system, the classical order laws (for example a PI type) can be insufficient for they are not robust, especially when the requirements on precision and other dynamic characteristics of the system are harsh. One must call upon order laws insensitive to the variations of parameters, to disruptions and to the nonlinearity.

The order by sliding mode possesses this robustness.

In this study, we present the model of the procedure as well as chosen algorithm for the estimation of the parameters. Next we develop the order law by sliding method.

We evaluate experimentally the performances of this order technique and its reaction after an external disruption applied to the procedure.

Presentation of the level regulation procedure: The studied procedure is a system of level regulation which is constituted of:

- Three reservoirs R1, R2 and R3 coupled by solenoid valves all or nothing
- Two analogical solenoid valves allowing to adjust both debits of the reservoirs supply

- Three ultrasound VEGASON61 sensors which are installed in the top of every reservoir

- Every reservoir is provided with a solenoid valve for evacuation

The system is described by the Fig. 1.

Reservoir R1 and R3 are identical. The central reservoir R2 has a bigger section.

Two solenoid valves all or nothing allow the reservoirs R1 and R3 to connect to reservoir R2.

A motor-pump immersed in a big reservoir $R_{V}$ allows to feed reservoirs R1 and R3 by adjusting the debits of their analogical valves.

\section{Identification of the process:}

Principle of the identification: This method is based on a criterion minimizing an error of prediction, which represents the distance between the release of the process and that predicted by the adjustable model. This minimization is made by means of an algorithm of optimization based on the Recursive Least Squares (RLS) technique and which allows obtaining an estimation of the parameter values.

Corresponding Author: Riadh Gamoudi, Laboratoire d'Analyse et Commande des Systèmes, 3100 ,

Manifacture de Tabac de Kairouan, Tunisie Tel : +216 97456070 


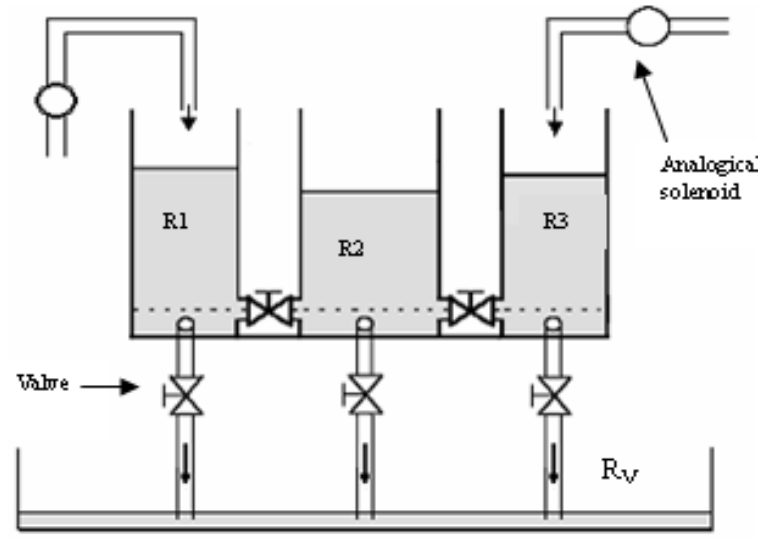

Fig. 1: Descriptive scheme of process

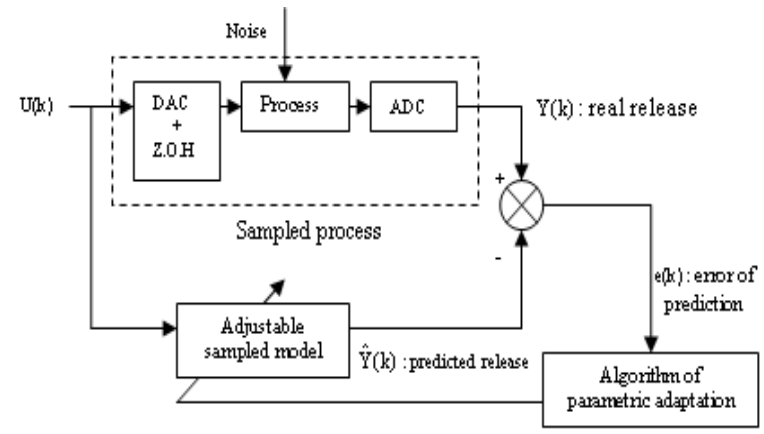

Fig. 2: Principle of the parametric adaptation

The principal plan of identification by the method of the error of prediction is the Fig. 2.

Model of the process: By leaving the model adopted by ${ }^{[1,2]}$ we have:

$$
\mathrm{A}\left(\mathrm{q}^{-1}\right) \mathrm{Y}(\mathrm{k})=\mathrm{B}\left(\mathrm{q}^{-1}\right) \mathrm{U}(\mathrm{k})+\mathrm{E}(\mathrm{k})
$$

Where:

$$
\mathrm{Y}(\mathrm{k})=\left(\begin{array}{c}
\mathrm{y}_{1}(\mathrm{k}) \\
\mathrm{y}_{2}(\mathrm{k}) \\
\mathrm{y}_{3}(\mathrm{k})
\end{array}\right), \mathrm{U}(\mathrm{k})=\left(\begin{array}{l}
\mathrm{u}_{1}(\mathrm{k}) \\
\mathrm{u}_{2}(\mathrm{k}) \\
\mathrm{u}_{3}(\mathrm{k})
\end{array}\right)
$$

and $\mathrm{E}(\mathrm{k})$ is a discreet white noise of useless average.

Matrices A (q-1) and B (q-1) are defined by:

$$
A\left(q^{-1}\right)=\left(\begin{array}{lll}
A_{11}\left(q^{-1}\right) & A_{12}\left(q^{-1}\right) & A_{13}\left(q^{-1}\right) \\
A_{21}\left(q^{-1}\right) & A_{22}\left(q^{-1}\right) & A_{23}\left(q^{-1}\right) \\
A_{31}\left(q^{-1}\right) & A_{32}\left(q^{-1}\right) & A_{33}\left(q^{-1}\right)
\end{array}\right)
$$

$$
B\left(q^{-1}\right)=\left(\begin{array}{ll}
B_{11}\left(q^{-1}\right) & B_{12}\left(q^{-1}\right) \\
B_{21}\left(q^{-1}\right) & B_{22}\left(q^{-1}\right) \\
B_{31}\left(q^{-1}\right) & B_{32}\left(q^{-1}\right)
\end{array}\right)
$$

With:

$$
\begin{aligned}
& \mathrm{A}_{\mathrm{ii}}\left(\mathrm{q}^{-1}\right)=1+\mathrm{a}_{\mathrm{ii}_{1}} \mathrm{q}^{-1}+\ldots+\mathrm{a}_{\mathrm{ii}_{\mathrm{n}_{\mathrm{ii}}}} \mathrm{q}^{-\mathrm{n}} \mathrm{ii} \\
& A_{i j}\left(q^{-1}\right)=a_{i j} q_{1} q^{-1}+a_{i j} q_{2} q^{-2}+\ldots+a_{i j_{n j}} q^{-n} i j \\
& B_{i j}\left(q^{-1}\right)=q^{-d i j}\left(b_{i j_{1}} q^{-1}+\ldots+b_{i j_{m_{i j}}} q^{-m} i j\right)
\end{aligned}
$$

So, this can allow to writing the out $\mathrm{y}_{\mathrm{i}}(\mathrm{k})$ under the following form:

$$
\mathrm{y}_{\mathrm{i}}(\mathrm{k})=-\sum_{\mathrm{j}=1 \mathrm{l}=1}^{3} \sum_{\mathrm{ij}}^{\mathrm{n}_{\mathrm{ij}}} \mathrm{a}_{\mathrm{ij}} \mathrm{y}_{\mathrm{j}}(\mathrm{k}-1)+\sum_{\mathrm{j}=1}^{2} \sum_{\mathrm{l}=1}^{\mathrm{m}_{\mathrm{ij}}} \mathrm{b}_{\mathrm{ij}_{1}} \mathrm{u}_{\mathrm{j}}\left(\mathrm{k}-1-\mathrm{d}_{\mathrm{ij}}\right)
$$

For $\mathrm{i}=1,2,3$

To estimate the complexity of a model, that is determining its order, some shape:

$$
\begin{aligned}
& y(k)=-a_{1} y(k-1)-\cdots-a_{n_{A}} y\left(k-n_{A}\right) \\
& +b_{1} u(k-1-d)+\cdots+b_{n_{B}} u\left(k-n_{B}-d\right)
\end{aligned}
$$

Using a matrix of instrumental variables $Z(\hat{n})$ whose elements are correlated with the best measures, but less or not correlated with noise.

The criterion used for the estimation of the complexity $\hat{\mathrm{n}}=\max \left(\hat{\mathrm{n}}_{\mathrm{A}}, \hat{\mathrm{n}}_{\mathrm{B}}+\hat{\mathrm{d}}\right)^{[3]}$ :

$$
\mathrm{CJ}_{\mathrm{IV}}(\hat{\mathrm{n}}, \mathrm{N})=\min _{\hat{\theta}} \frac{1}{\mathrm{~N}}\|\mathrm{Y}(\mathrm{N})-\mathrm{Z}(\hat{\mathrm{n}}) \hat{\theta}\|^{2}+\frac{2 \hat{\mathrm{n}} \log \mathrm{N}}{\mathrm{N}}
$$

Where

$$
\hat{\mathrm{n}}=\min _{\hat{\mathrm{n}}} \mathrm{CJ} I V(\hat{\mathrm{n}})
$$

With:

$$
\begin{gathered}
\mathrm{Z}(\hat{\mathrm{n}})=[\mathrm{U}(\mathrm{k}-\mathrm{L}-1), \mathrm{U}(\mathrm{k}-1), \mathrm{U}(\mathrm{k}-\mathrm{L}-2), \\
\mathrm{U}(\mathrm{k}-2), \cdots, \mathrm{U}(\mathrm{k}-\mathrm{L}-\hat{\mathrm{n}}), \mathrm{U}(\mathrm{k}-\hat{\mathrm{n}})] \\
\mathrm{U}^{\mathrm{T}}(\mathrm{k})=[\mathrm{u}(\mathrm{k}), \mathrm{u}(\mathrm{k}-1), \cdots]
\end{gathered}
$$


$\mathrm{Y}^{\mathrm{T}}(\mathrm{N})=[\mathrm{y}(\mathrm{N}), \mathrm{N}(\mathrm{N}-1), \ldots] \mathrm{N}$ is the data number.

Algorithm of estimation parameters: We are going to use a recursive algorithm to identify the parameters of our process. The formulation of this algorithm of identification uses the quadratic criterion to minimize the prediction error and the Recursive Least Squares technique to calculate the estimation parameters. Thus the name: the Recursive Least Squares identification algorithm (RLS).

The steps of the RLS are the following ${ }^{[4]}$ :

- Calculation of the recursive estimation

$$
\hat{\theta}_{\mathrm{i}}(\mathrm{k})=\hat{\theta}_{\mathrm{i}}(\mathrm{k}-1)+\mathrm{P}_{\mathrm{i}}(\mathrm{k}) \Phi_{\mathrm{i}}(\mathrm{k}) \mathrm{e}_{\mathrm{i}}(\mathrm{k})
$$

- Update the gain of adaptation

$$
\mathrm{P}_{\mathrm{i}}(\mathrm{k})=\mathrm{P}_{\mathrm{i}}(\mathrm{k}-1)-\frac{\mathrm{P}_{\mathrm{i}}(\mathrm{k}-1) \Phi_{\mathrm{i}}(\mathrm{k}) \Phi_{\mathrm{i}}{ }^{\mathrm{T}}(\mathrm{k}) \mathrm{P}_{\mathrm{i}}(\mathrm{k}-1)}{1+\Phi_{\mathrm{i}}{ }^{\mathrm{T}}(\mathrm{k}) \mathrm{P}_{\mathrm{i}}(\mathrm{k}-1) \Phi_{\mathrm{i}}(\mathrm{k})}
$$

- Calculation of the error of prediction

$$
\mathrm{e}_{\mathrm{i}}(\mathrm{k})=\mathrm{y}_{\mathrm{i}}(\mathrm{k})-\hat{\theta}_{\mathrm{i}}^{\mathrm{T}}(\mathrm{k}-1) \Phi_{\mathrm{i}}(\mathrm{k})
$$

Remark1: To give more weight to the new observations and ignore progressively the former information, we introduce ponderation $\lambda_{1}(\mathrm{k})$ and $\lambda_{2}(\mathrm{k})$ in the updating equation of adaptation matrix gain $\mathrm{P}_{\mathrm{i}}$ $(\mathrm{k})^{[4]}$.

$$
\mathrm{P}_{\mathrm{i}}(\mathrm{k})=\frac{1}{\lambda_{1}(\mathrm{k})}\left[\mathrm{P}_{\mathrm{i}}(\mathrm{k}-1)-\frac{\mathrm{P}_{\mathrm{i}}(\mathrm{k}-1) \Phi_{\mathrm{i}}(\mathrm{k}) \Phi_{\mathrm{i}}^{\mathrm{T}}(\mathrm{k}) \mathrm{P}_{\mathrm{i}}(\mathrm{k}-1)}{\frac{\lambda_{1}(\mathrm{k})}{\lambda_{2}(\mathrm{k})}+\Phi_{\mathrm{i}}^{\mathrm{T}}(\mathrm{k}) \mathrm{P}_{\mathrm{i}}(\mathrm{k}-1) \Phi_{\mathrm{i}}(\mathrm{k})}\right]
$$

We chose a factor of time-varying oversight. We set

$$
\begin{aligned}
& \lambda_{2}(\mathrm{k})=1 \text { and the factor of oversight is given by: } \\
& \lambda_{1}(\mathrm{k})=\lambda_{0} \lambda_{1}(\mathrm{k}-1)+\left(1-\lambda_{0}\right) \\
& \lambda_{1}(0)=\lambda_{1}(0.95 \ldots 0.99) \text { and } \lambda_{0}(0.95 \ldots 0.99)
\end{aligned}
$$

Principle of the sliding mode command: The command by sliding mode consists in transporting the states of the system in a suitably selected region, then to conceive a command capable to maintain the system in this region. In general the conception of a command by sliding mode requires mainly three steps ${ }^{[5,6]}$ :

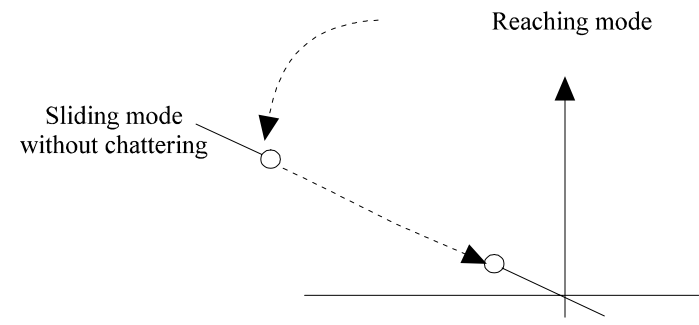

Fig. 3: Various modes for the trajectory

- Determination of a space state region such as the system has the wished behavior

- The convergence conditions are realized to force the representative points of the trajectory to converge on the sliding surfaces ${ }^{[7]}$

- Research a law of order which drives the system up to this space state region then toward its equilibrium point by maintaining the condition of existence of the sliding mode.

The sliding modes: The command by sliding mode creates three phases ${ }^{[8]}$.

- The Reaching mode: it consists in returning the state of the system since its initial position $\mathrm{x}(0)=$ $\mathrm{x} 0$ to the surface of gliding at finished time

- The Sliding mode: the state towards the point of balance with a dynamics defined by the surface of sliding consists in making tighten asymptotic

- The mode of permanent regime: consists in studying the behavior of the system around the equilibrium point (Fig. 3).

Sliding surfaces: The choice of the sliding surface concerns not only the necessary number of surfaces, but equally their form and this in function of the application and the aimed at objective. Thus, the surface $\mathrm{S}(\mathrm{x})$ represents -itself- the desired dynamic behaviour of the system. Slotine ${ }^{[9]}$ proposes a form of a general equation to determine the sliding surface assuring the convergence of a variable towards its desired value.

$$
\mathrm{S}(\mathrm{x})=\left(\frac{\partial}{\partial \mathrm{t}}+\lambda\right)^{\mathrm{n}-1} \mathrm{e}(\mathrm{x})
$$

Where:

$\mathrm{e}(\mathrm{x})=$ Various of the variable to regulate $\mathrm{e}(\mathrm{x})=\mathrm{x}_{\mathrm{d}}-\mathrm{x}$

$\lambda=$ Positive constant which interprets the passing and of the desired control 
$\mathrm{n}=$ Relative degree, which equals the number of times that should be derived the exit to make the command appear

Discreet command by sliding mode: Once the problem of existence is resolved by fixing the dynamics wished by the system in sliding mode and it by the choice of a sliding surface (matrix S) stable, we pass in the second stage which consists in the synthesis of nonlinear laws of command $\mathrm{u}=\mathrm{f}(\mathrm{x})$ leading the trajectory of state on the sliding surface at time finished and forcing her to stay on this surface.

Generally, the law of command consists of two $\operatorname{parts}^{[10,11]}$ :

- A linear component by return of state of the shape $\mathrm{u} \mathrm{L}(\mathrm{x})=\mathrm{K} \mathrm{x}$

- A non linear component of the command u N (x) introducing a discontinuous element

Let us consider the following discreet linear variable multi-system:

$$
\mathrm{x}(\mathrm{k}+1)=\mathrm{Ax}(\mathrm{k})+\mathrm{Bu}(\mathrm{k})
$$

Where:

$\mathrm{x}=\left[\begin{array}{llll}\mathrm{x}_{1} & \mathrm{x}_{2} & \ldots & \mathrm{x}_{\mathrm{n}}\end{array}\right]^{\mathrm{T}} \in \mathfrak{R}^{\mathrm{n}}$ The state vector

$\mathrm{u}=\left[\begin{array}{llll}\mathrm{u}_{1} & \mathrm{u}_{2} & \ldots & \mathrm{u}_{\mathrm{m}}\end{array}\right]^{\mathrm{T}} \in \mathfrak{R}^{\mathrm{m}}$ The input vector

$\mathrm{A}$ and $\mathrm{B}$ are constant matrices with the appropriate dimensions.

By using the transformations $\mathrm{T}$ and $\mathrm{T} 2$ such as $\mathrm{y}=\mathrm{Tx}$ and $\mathrm{z}=\mathrm{T}_{2} \mathrm{y}$

$$
\mathrm{T}_{2}=\left[\begin{array}{cc}
\mathrm{I}_{\mathrm{n}-\mathrm{m}} & 0 \\
\mathrm{~F} & \mathrm{I}_{\mathrm{m}}
\end{array}\right]
$$

Then the system spells under the following shape:

$$
\begin{aligned}
& \mathrm{z}_{1}(\mathrm{k}+1)=\sum_{1} \mathrm{z}_{1}(\mathrm{k})+\sum_{2} \mathrm{z}_{2}(\mathrm{k}) \\
& \mathrm{z}_{2}(\mathrm{k}+1)=\sum_{3} \mathrm{z}_{1}(\mathrm{k})+\sum_{4} \mathrm{z}_{2}(\mathrm{k})+\mathrm{B}_{2} \mathrm{u}(\mathrm{k})
\end{aligned}
$$
out:

The linear constituent of the command is spelled

$$
\mathrm{u}_{\mathrm{L}}(\mathrm{x})=-\mathrm{B}_{2}^{-1}\left[\sum_{3}\left(\Sigma 4^{-} \sum_{4}^{*}\right)\right] \mathrm{T}_{2} \mathrm{Tx}=\mathrm{Kx}
$$

Where

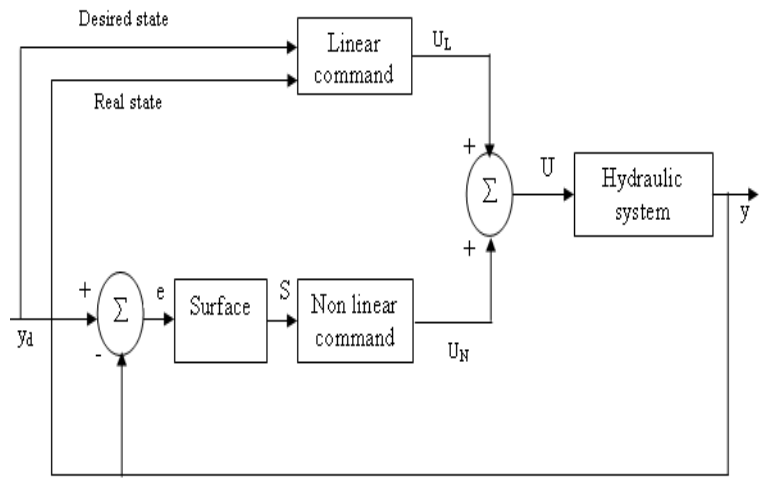

Fig. 4: Schematic bloc of the order

$$
\mathrm{K}=-\mathrm{B}_{0}^{-1}\left[\sum_{3}\left(\sum_{4}-\Sigma_{4}^{*}\right)\right] \mathrm{T}_{2} \mathrm{~T}
$$

$\Sigma_{4}^{*}$ is an $\mathrm{m} \times \mathrm{m}$ matrix that all the appropriate values of which are inside the unity circle. In particular, we can choose:

$$
\Sigma_{4}^{*}=\operatorname{diag}\left\{\lambda_{\mathrm{i}}, \mathrm{i}=1 \ldots \mathrm{m}\right\} /\left|\lambda_{\mathrm{i}}\right|<1
$$

Consider the Lyapunov function

$$
\mathrm{V}\left(\mathrm{z}_{2}\right)=\frac{1}{2}\left(\mathrm{z}_{2} \mathrm{P} \mathrm{z}_{2}\right)=\frac{1}{2} \mathrm{z}_{2}{ }^{\mathrm{t}} \mathrm{P} \mathrm{z}_{2}
$$

with $\mathrm{P}$ a symmetric matrix defined positive which verifies:

$$
\sum_{4}^{* \mathrm{~T}} \mathrm{P} \sum_{4}^{*}-\mathrm{P}=-\mathrm{I}_{\mathrm{m}}
$$

For the non-linear constituent we take:

$$
\begin{aligned}
& u_{N}(z)=-\rho \frac{B_{2}^{-1} \mathrm{Pz}_{2}}{\left\|P z_{2}\right\|} \quad \text { if } z_{2} \neq 0 \\
& \left\|u_{N}(z)\right\| \leq \rho \quad \text { if } z_{2}=0
\end{aligned}
$$

$\mathrm{p}>0$ is a parameter of synthesis

The command u (Fig. 4) is equal to:

$$
\mathrm{u}(\mathrm{x})=\mathrm{u}_{\mathrm{L}}(\mathrm{x})+\mathrm{u}_{\mathrm{N}}(\mathrm{x})
$$

\section{MATERIALS AND METHODS}

We proceeded to the verification and the test of the developed order in experimentation to the system of 


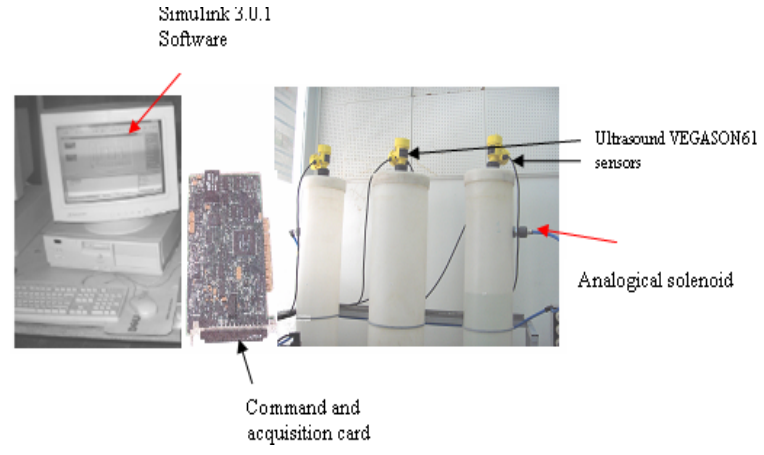

Fig. 5: General view of the used equipment

coupled reservoirs (Fig. 5). The command is established using a PC Pentium III to $800 \mathrm{MHZ}$ equipped of a card PCIDAS -1002 and software Matlab 5.3.0 with Simulink 3.0.1

The idea consist in to realize an instantaneous acquisition of the level regulation in the middle reservoir using the ultrasonic sensors and to compare at the value that represents the zone of the stability of the system. If this value is not attained again, they analogical solenoid valves, set up on the extremities of the other reservoirs, release of an automatic manner in order to compensate this difference. Once the surface of stability is attained, we injects an external perturbation on the system by the opening the solenoid valve for evacuation that exists at the bottom of the central reservoir, the order must react again of such sort that she must be able to maintain the same zone of stability.

The sliding order law, is able to vary according to the need the debit of they analogical solenoid valves and to release them of an automatic manners whenever she necessary. She was developed while using the Simulink 3.0.1 tool of Matlab and she was established using the card PCIDAS-1002.

\section{RESULTS}

We have choice to apply two excitement signals in the process, that is given by its following real output (Fig. 6), to realize the identification:

- Pseudorandom Binary Sequence (PRBS), signal rich in frequency which guarantees a good estimation of the parameters (Fig. 7).

- Periodic signal (Fig. 8), inciting the process constantly and allowing to produce by combining it with the previous signal every possible zones of excitement. These two signals are respectively represented in (Fig. 4 and 5).

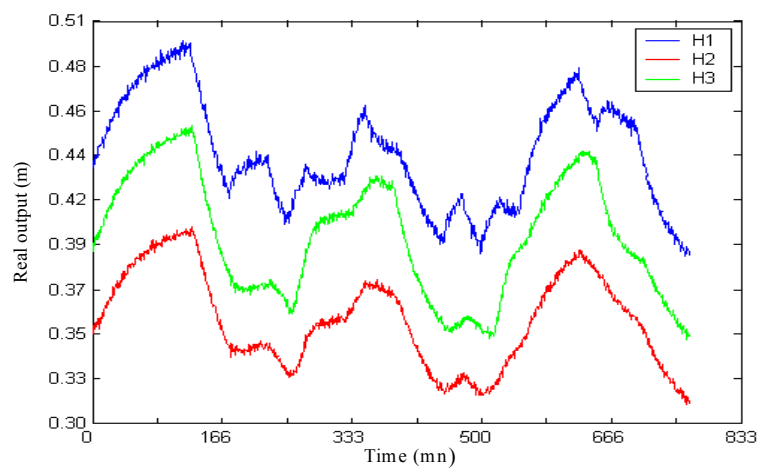

Fig. 6: Real answers

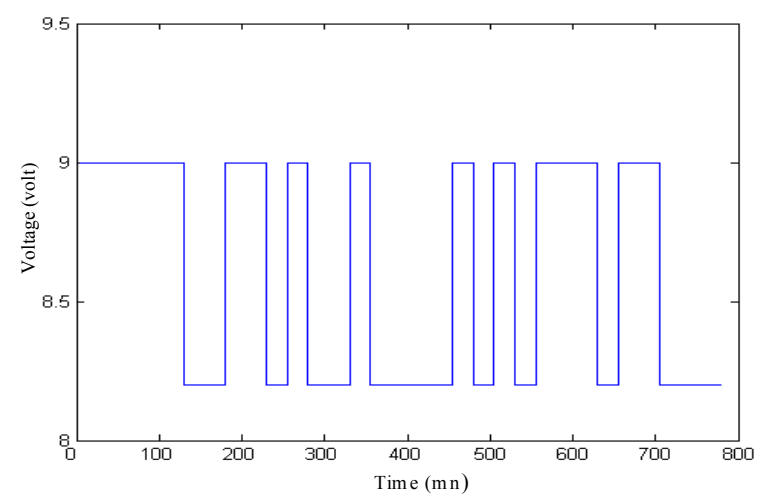

Fig. 7: PRBS signal

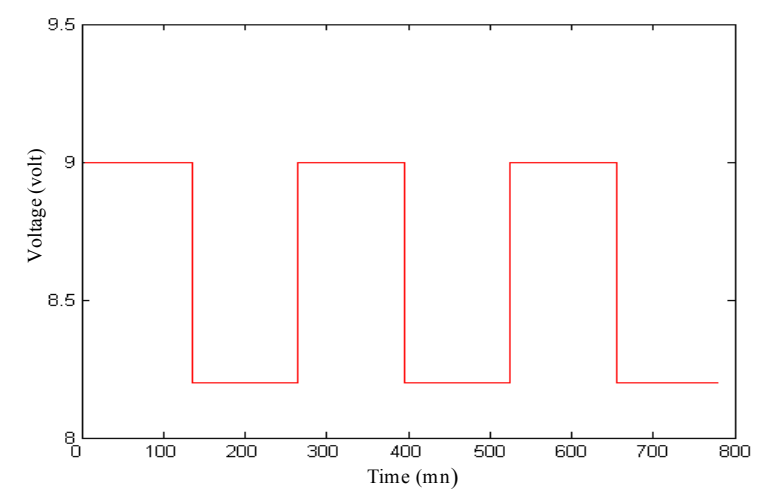

Fig. 8: Periodic signal

We have realized two essays. During every try we applied the PRBS to a proportional solenoid valve and a periodic signal on the other one. The real obtained answers (the heights in three reservoirs $\mathrm{H} 1, \mathrm{H} 2$ and $\mathrm{H} 3$ ) during the first essay are represented below:

By applying the Recursive Least Squares algorithm (RLS), we can so determine the coefficients of the model of the process. 


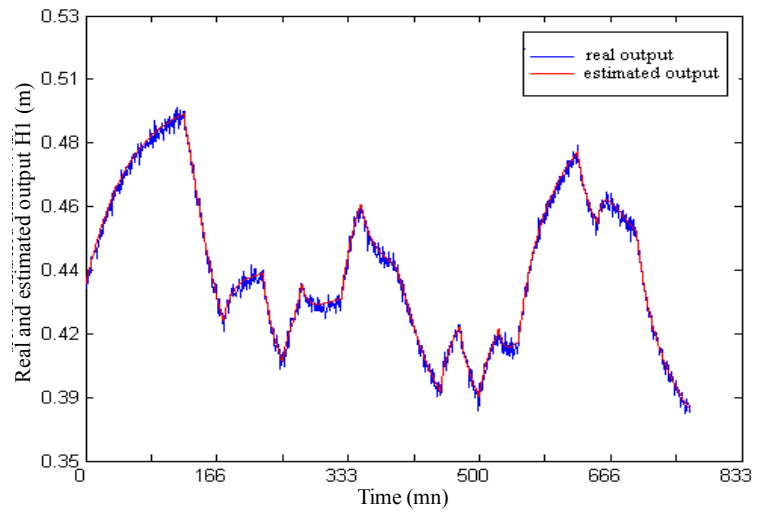

Fig. 9: Real and estimated answers to H1

The curves of the real answers and the estimated answers, as well as the error of prediction, obtained during the identification are:

The representation of state of the considered system is the following:

$$
\begin{aligned}
& x(k+1)=A x(k)+B u(k) \\
& y(k)=C x(k)
\end{aligned}
$$

With

$$
\begin{aligned}
A & =\left[\begin{array}{cccc}
1.2071 & -0.0179 & -0.1214 & -0.0292 \\
0.0669 & 0.7933 & -0.2350 & 0.2912 \\
-0.5011 & 0.4257 & 0.0830 & 0.5759 \\
0.5132 & 0.1959 & -0.4138 & 0.8121
\end{array}\right] \\
B & =\left[\begin{array}{cc}
0.0125 & 0.0171 \\
0.0563 & 0.0016 \\
0.0134 & 0.0111 \\
-0.00270 .0526
\end{array}\right] \quad C=\left[\begin{array}{l}
0100 \\
0010 \\
0001
\end{array}\right]
\end{aligned}
$$

This system is commendable and observable. The matrix of orthogonal transformation $\mathrm{T}$ is the following one:

$$
\mathrm{T}=\left[\begin{array}{cccc}
-0.8694 & 0.2687 & -0.2540 & 0.3278 \\
-0.3450 & -0.1475 & 0.9236 & -0.0783 \\
0.1516 & -0.5009 & 0.0488 & 0.8507 \\
-0.3196 & -0.8094 & -0.2828 & -0.4034
\end{array}\right]
$$

We have obtained $\mathrm{m}=2$

So the return state matrix of the reduced system F.

$$
\mathrm{F}=\left[\begin{array}{cc}
130.8751 & 14.8746 \\
86.5465 & 14.1994
\end{array}\right]
$$

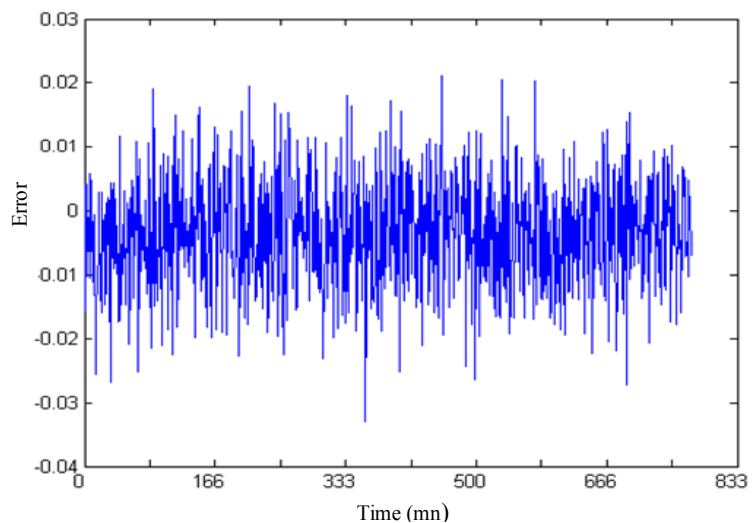

Fig. 10: Error of prediction

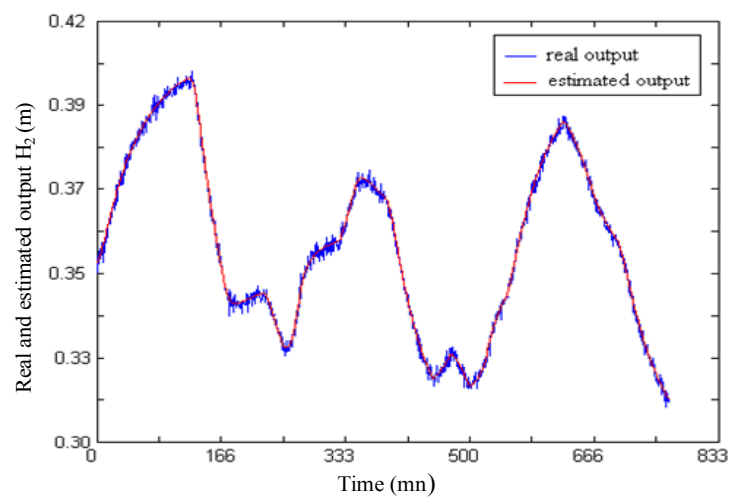

Fig. 11: Real and estimated answers to $\mathrm{H} 2$

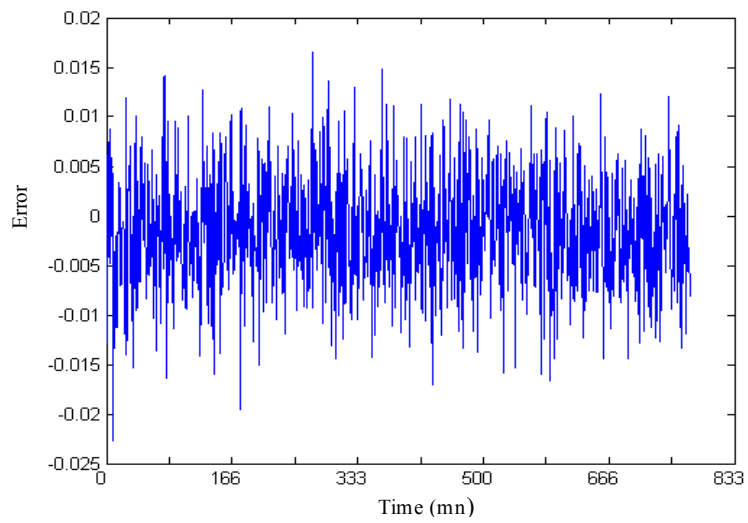

Fig. 12: Error of prediction

The matrix which defines the hyper surface of sliding is given by:

$$
S=\left[\begin{array}{rrrr}
-118.76 & 32.47 & -19.45 & 42.58 \\
-80.46 & 20.35 & -9.15 & 26.85
\end{array}\right]
$$




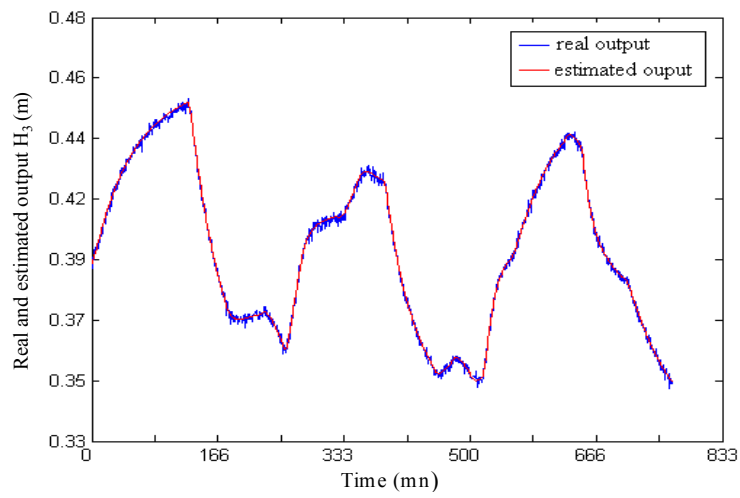

Fig. 13: Real and estimated answers to $\mathrm{H} 3$

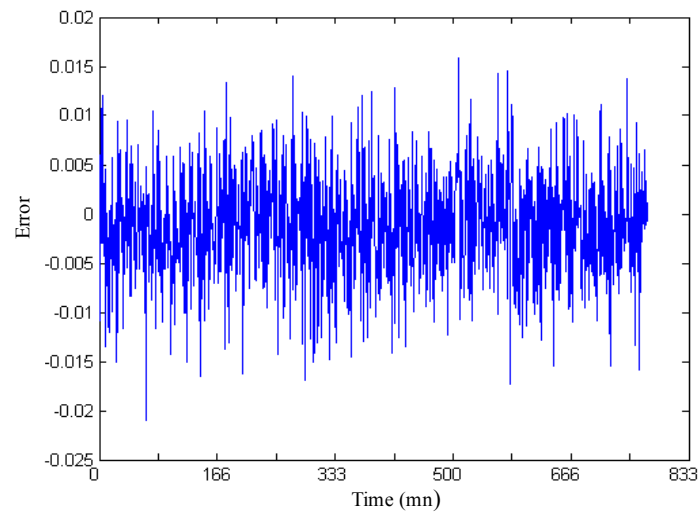

Fig. 14: Error of prediction

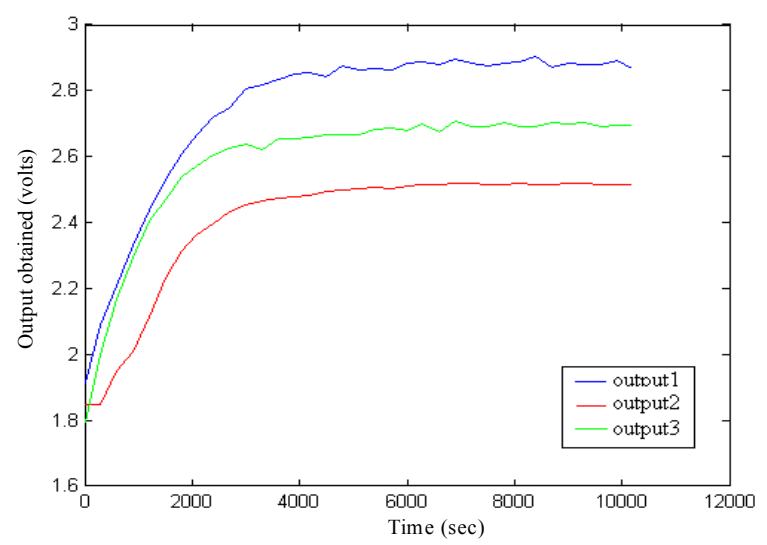

Fig. 15: Evolution of the system releases

The obtained releases are the following ones:

The commands applied to the system are drawn in (Fig. 16).

The evolution of the switching functions is given by (Fig. 17).

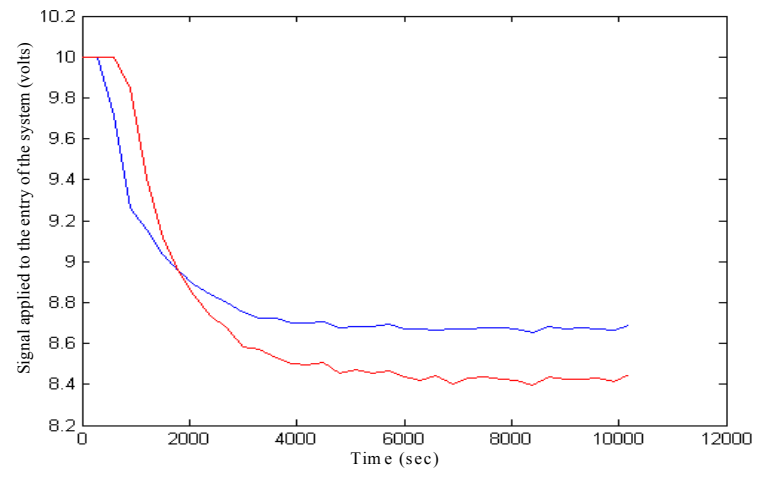

Fig. 16: Commands applied to the entry of the system

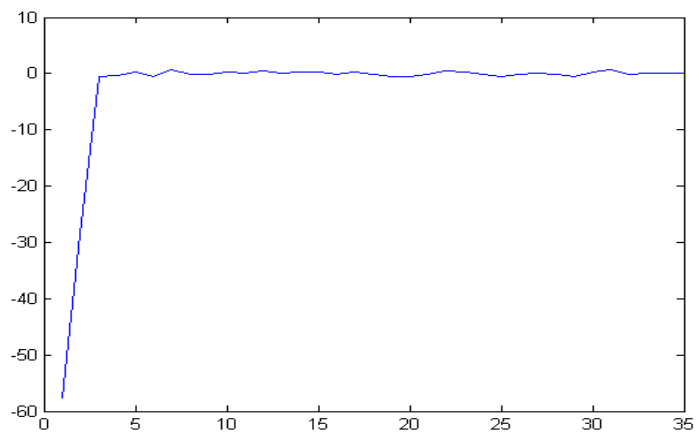

Fig. 17: Evolution of the switching surface

\section{DISCUSSION}

In the first party we proceeded to modelling and identified the system, the Fig. $(9,11,13)$ show well the robustness of RLS algorithm, in view of the fact that the difference between the real and the estimated answers is on the order of 0.01 (Fig. 10, 12, 14).

In the second party, we was interested in order establishment by sliding mode of such sort that she must be capable to vary of an automatic manner the entry of the procedure, the two analogical solenoid valves debit, (Fig. 16) in order to ensure a level regulation around a equilibrium point in the stability zone (Fig. 15).

\section{CONCLUSION}

In this research, we identified the process established by coupled reservoirs, around a point of functioning.

By using the Recursive Least Squares algorithm, we determined the coefficients of the model.

The experimental results show the good performance of this algorithm. 
So, the obtained models allowing to elaborate an order laws which we can apply to the process.

The order applied to the process is a discreet command by sliding mode.

By introducing an external perturbation this command proved a robustness, it permit to bring the state variable to the sliding surface, otherwise to the stability zone (Fig. 15).

According to the obtained results, the hardiness of the order has been proved as a result of the introduction of an external perturbation on the process.

So, the found results approved the experimental tests support the theoretical development.

\section{REFERENCES}

1. Guidorzi, R., 1975. Canonical structure in the identification of multivariable systems. Automatica, 11: 361-374. Doi: 10.1016/00051098(75)90085-0

2. El-Sherief, H. and N.K. Sinha, 1979. Identification and modeling for linear multivariable discrete time systems: a survey. J. Cybernetics Syst., 9: 43-71. Doi: 10.1080/01969727908927593

3. Duong, H. and I.D. Landau, 1996. An IV based criterium for model order selection. Automatica, 32: 909-914. Doi: 10.1016/0005-1098(96)00020-9

4. Ben Abdennour, R., P. Borne, M. Ksouri and F. M'Sahli, 2001. Identification and Digital Control of the Industrial Procedures. 1st Edn., Collection Methods and Practical of Engineer. Technip, ISBN: 2-7108-0798-X.

5. Adamy, J. and A. Flemming, 2004. Soft variable-structure controls: A survey. Automatica, 40: 1821-1844. Doi: 10.1016/j.automatica.2004. 05.017
6. Healy, A.J. and D. Leonard, 1993. Multivariable sliding mode control for autonomous diving and steering of unmanned underwater vehicles. IEEE J. Oceanic Eng., 18: 327-339. Doi: 10.1109/JOE.1993.236372

7. Chung-Yuen, W., D.H. Kim, and B.K. Bose, 1992. An induction motor servo system with improved sliding mode control. Industrial Electronics, Control, Instrumentation, and Automation, 1992. Power Electronics and Motion Control. Proceedings of the 1992 International Conference on. 1: 60-66. Doi: 10.1109/IECON.1992.254604

8. Kechich, A., B. Mazari, and I.K. Bousserhane, 2007. Application of nonlinear sliding-mode control to permanent magnet synchronous machine. Int. J. Applied Eng. Res., 2: 125-138. http://www.ripublication.com/ijaerv2/ijaerv2n1_9. pdf

9. Her-Terng, Y. and J.J. Yan, 2004. Design of sliding mode controller for Lorenz chaotic system with nonlinear input. Elsevier Ltd., 19: 891-898. Doi: 10.1016/S0960-0779(03)00255-8

10. Zhanga, H., G. Duanb, and L. Xie, 2005. Linear quadratic regulation for linear time-varying systems with multiple input delays. In: Control and Automation, 2005. ICCA '05. International Conference, June 27-29, 2005. Budapest, Hungary. 2: 948-953. Doi: 10.1109/ICCA.2005.1528258

11. Edwards, C., NO. Lai, and SK. Spurgeon, 2005. On discrete dynamic output feedback min-max controllers. Automatica, 41: 1783-1790. Doi: 10.1016/j.automatica.2005.05.003 